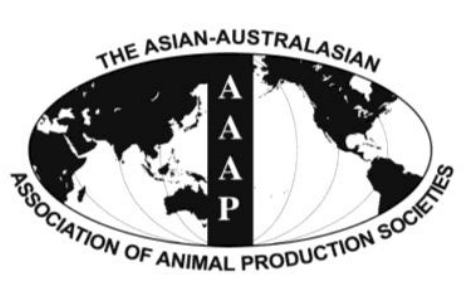

Open Access

Asian Australas. J. Anim. Sci.

Vol. 28, No. 2 : 239-246 February 2015

http://dx.doi.org/10.5713/ajas.14.0330

www.ajas.info

pISSN 1011-2367 elSSN 1976-5517

\title{
Effect of Bacillus amyloliquefaciens-based Direct-fed Microbial on Performance, Nutrient Utilization, Intestinal Morphology and Cecal Microflora in Broiler Chickens
}

\author{
Xinjian Lei ${ }^{1,2}$, Xiangshu Piao ${ }^{2, *}$, Yingjun Ru ${ }^{1}$, Hongyu Zhang ${ }^{2}$, Alexandre Péron ${ }^{3}$, and Huifang Zhang ${ }^{1}$ \\ ${ }^{1}$ College of Animal Science and Technology, Gansu Agricultural University, Lanzhou 730070, China
}

\begin{abstract}
The present study was conducted to evaluate the effect of the dietary supplementation of Bacillus amyloliquefaciensbased direct-fed microbial (DFM) on growth performance, nutrient utilization, intestinal morphology and cecal microflora in broiler chickens. A total of two hundred and eighty eight 1-d-old Arbor Acres male broilers were randomly allocated to one of four experimental treatments in a completely randomized design. Each treatment was fed to eight replicate cages, with nine birds per cage. Dietary treatments were composed of an antibiotic-free basal diet (control), and the basal diet supplemented with either $15 \mathrm{mg} / \mathrm{kg}$ of virginiamycin as antibiotic growth promoter (AGP), $30 \mathrm{mg} / \mathrm{kg}$ of Bacillus amyloliquefaciens-based DFM (DFM 30) or $60 \mathrm{mg} / \mathrm{kg}$ of Bacillus amyloliquefaciens-based DFM (DFM 60). Experimental diets were fed in two phases: starter (d 1 to 21 ) and finisher (d 22 to 42). Growth performance, nutrient utilization, morphological parameters of the small intestine and cecal microbial populations were measured at the end of the starter (d 21) and finisher (d 42) phases. During the starter phase, DFM and virginiamycin supplementation improved the feed conversion ratio (FCR; $\mathrm{p}<0.01)$ compared with the control group. For the finisher phase and the overall experiment $(\mathrm{d}$ 1 to 42) broilers fed diets with the DFM had better body weight gain (BWG) and FCR than that of control (p<0.05). Supplementation of virginiamycin and DFM significantly increased the total tract apparent digestibility of crude protein (CP), dry matter (DM) and gross energy during both starter and finisher phases $(\mathrm{p}<0.05)$ compared with the control group. On $\mathrm{d} 21$, villus height, crypt depth and villus height to crypt depth ratio of duodenum, jejunum, and ileum were significantly increased for the birds fed with the DFM diets as compared with the control group ( $\mathrm{p}<0.05$ ). The DFM 30, DFM 60, and AGP groups decreased the Escherichia coli population in cecum at $\mathrm{d} 21$ and d 42 compared with control group ( $<<0.01$ ). In addition, the population of Lactobacillus was increased in DFM 30 and DFM 60 groups as compared with control and AGP groups ( $\mathrm{p}<0.01$ ). It can be concluded that Bacillus amyloliquefaciens-based DFM could be an alternative to the use of AGPs in broilers diets based on plant protein. (Key Words: Bacillus amyloliquefaciens, Broilers, Cecal Microflora, Intestinal Morphology, Nutrient Utilization, Performance)
\end{abstract}

\section{INTRODUCTION}

Increasing concerns regarding antibiotic resistance and the presence of drug residues in animal products have led several European countries and South Korea to ban the use

\footnotetext{
* Corresponding Author: Xiangshu Piao. Tel: +86-10-62733577, Fax: +86-10-62733688, E-mail: piaoxsh@mafic.ac.cn

2 State Key Laboratory of Animal Nutrition, Ministry of Agriculture Feed Industry Certre, China Agricultural University, Beijing 100193, China.

${ }^{3}$ Danisco Animal Nutrition, Science Park III, Singapore, 17525, Singapore.

Submitted May 7, 2014; Revised Jul. 3, 2014; Accepted Aug. 1, 2014
}

of antibiotic growth promoters (AGPs) in animal feed (Castanon, 2007; Alloui et al., 2013). However, it is feared that the ban of AGPs may have adverse consequences for animal health and farmers' profits. This has triggered a search for viable alternatives to AGPs in the animal industry, and direct-fed microbials (DFMs) have serious potential for this application (Hong et al., 2005).

DFMs were defined as "live microbial feed supplements which beneficially affect the host animal by improving its intestinal balance" (Fuller, 1989). Promising results have been found upon the application of DFMs in the poultry industry (Ferreira et al., 2011). The supplementation of various DFMs has been shown to diversify and stabilize 
gastrointestinal microbiota (An et al., 2008), in addition to improving animal production and health (Aliakbarpour et al., 2012). However, the effectiveness of DFMs in animal studies varies greatly depending on the origin of the microbes (Jerzsele et al., 2012).

Lactobacillus species, yeast species and spore-forming bacteria such as Bacillus species are the species used as DFMs (Huyghebaert et al., 2011). Bacillus amyloliquefaciens is a member of genus Bacillus, however, limited studies have been conducted to assess the efficacy of Bacillus amyloliquefaciens for broiler chickens. Therefore, the objective of the present study was to evaluating the effect of Bacillus amyloliquefaciens-based DFM supplementation in broilers diets on performance, nutrient utilization, morphological development of the small intestine and cecal microflora population.

\section{MATERIALS AND METHODS}

The Animal Welfare Committee of China Agricultural University approved the animal care protocol used for this experiment.

\section{Direct-fed microbial}

The Bacillus amyloliquefaciens-based DFM product was supplied by Danisco Animal Nutrition, and it contains three strains of Bacillus amyloliquefaciens. The concentration of living microbes was $2.5 \times 10^{9} \mathrm{cfu} / \mathrm{g}$ of product.

\section{Birds, diets, and experimental design}

Two hundred and eighty-eight 1-d-old male Arbor Acres broiler chickens hatched at Beijing Arbor Acres Poultry Breeding Co., Ltd. (Beijing, China) were wing-banded upon arrival, weighed and randomly allocated to four experimental treatments. Each treatment group consisted of eight replicates with nine birds per replicate. Birds were raised in wire-floored cages placed into an environmentally controlled room with continuous lighting and had ad libitum access to feed and water for the entire 42-day experimental period. The room temperature was maintained at $33^{\circ} \mathrm{C}$ for the first three days, and then gradually reduced by $3^{\circ} \mathrm{C}$ a week until reaching $24^{\circ} \mathrm{C}$. During the trial, average relative humidity remained within a $60 \%$ to $65 \%$ range. Birds were inoculated with Newcastle disease vaccine on $\mathrm{d} 7$ and 28 and with inactivated infectious bursa disease vaccine on $\mathrm{d} 14$ and 21 .

The four dietary treatments were composed of an antibiotic-free basal diet (control), basal diet supplemented with $30 \mathrm{mg} / \mathrm{kg} \quad\left(7.5 \times 10^{7} \quad \mathrm{cfu} / \mathrm{kg}\right)$ of Bacillus amyloliquefaciens-based DFM (DFM 30), basal diet supplemented with $60 \mathrm{mg} / \mathrm{kg}\left(1.5 \times 10^{8} \mathrm{cfu} / \mathrm{kg}\right)$ of Bacillus amyloliquefaciens-based DFM (DFM 60), and basal diet supplemented with $15 \mathrm{mg} / \mathrm{kg}$ of virginiamycin (AGP). Both starter (d 1 to 21) and finisher (d 22 to 42) diets (Table 1) were fed in mash form and formulated to meet nutrient requirements of broiler chickens (NRC, 1994).

\section{Sampling and sample processing procedure}

On d 21 and 42, broilers were fasted for $12 \mathrm{~h}$ and body weights and feed residues were measured on a cage basis in order to determine body weight gain (BWG) and feed intake (FI) values. Feed conversion ratio (FCR) was calculated accordingly.

Feed samples from each treatment and feeding phase were collected at the beginning of the experiment. Two digestibility trials were performed on d 19 and d 40, using chromic oxide as an indigestible marker. Excreta were collected between d 19 and d 21 and d 40 and d 42 on a cage basis, and oven-dried at $65^{\circ} \mathrm{C}$ for $72 \mathrm{~h}$. Feed and dried excreta samples were then stored at $4^{\circ} \mathrm{C}$ prior to chemical

Table 1. Composition and nutrient levels of basal diets (as-fed basis)

\begin{tabular}{|c|c|c|}
\hline Item & $\begin{array}{c}\text { Starter } \\
\text { (d1 to } 21)\end{array}$ & $\begin{array}{l}\text { Finisher } \\
\text { (d } 22 \text { to } 42 \text { ) }\end{array}$ \\
\hline \multicolumn{3}{|l|}{ Ingredient $(\%)$} \\
\hline Corn & 56.20 & 61.43 \\
\hline Soybean meal & 24.00 & 14.36 \\
\hline Rapeseed meal & 3.00 & 4.70 \\
\hline Cottonseed meal & 3.00 & 4.70 \\
\hline Corn gluten meal & 6.20 & 6.85 \\
\hline Soybean oil & 2.35 & 3.20 \\
\hline Dicalcium phosphate & 1.65 & 1.18 \\
\hline Limestone & 1.47 & 1.50 \\
\hline Salt & 0.45 & 0.35 \\
\hline L-lysine $\cdot \mathrm{HCl}(78 \%)$ & 0.28 & 0.35 \\
\hline Methionine hydroxy analogue $(84 \%)$ & 0.15 & 0.13 \\
\hline Premix $^{1}$ & 1.00 & 1.00 \\
\hline Chromic oxide & 0.25 & 0.25 \\
\hline \multicolumn{3}{|l|}{ Nutrient levels ${ }^{2}(\%)$} \\
\hline Metabolizable energy (kcal/kg) & 2,950 & 3,050 \\
\hline Crude protein & 21.50 & 19.50 \\
\hline Calcium & 1.00 & 0.90 \\
\hline Total phosphorus & 0.67 & 0.58 \\
\hline Available phosphorus & 0.45 & 0.36 \\
\hline Digestible lysine & 1.04 & 1.01 \\
\hline Digestible methionine & 0.45 & 0.41 \\
\hline Digestible tryptophan & 0.20 & 0.16 \\
\hline Digestible threonine & 0.65 & 0.56 \\
\hline Digestible methionine and cysteine & 0.78 & 0.72 \\
\hline
\end{tabular}

${ }^{1}$ Premix supplied per kg diet: vitamin A, 11,000 IU; vitamin D, 33,025 $\mathrm{IU}$; vitamin E, $22 \mathrm{mg}$; vitamin $\mathrm{K}_{3}, 2.2 \mathrm{mg}$; vitamin $\mathrm{B}_{1}, 1.65 \mathrm{mg}$; vitamin $\mathrm{B}_{2}, 6.6 \mathrm{mg}$; vitamin $\mathrm{B}_{6}, 3.3 \mathrm{mg}$; vitamin $\mathrm{B}_{12}, 17.6 \mu \mathrm{g}$; nicotinic acid, 22 $\mathrm{mg}$; pantothenic acid, $13.2 \mathrm{mg}$; folic acid, $0.33 \mathrm{mg}$; biotin, $88 \mu \mathrm{g}$; choline chloride, $500 \mathrm{mg}$; iron, $48 \mathrm{mg}$; zinc, $96.6 \mathrm{mg}$; manganese, $101.76 \mathrm{mg}$; copper, $10 \mathrm{mg}$; selenium, $0.05 \mathrm{mg}$; iodine, $0.96 \mathrm{mg}$; cobalt, $0.3 \mathrm{mg}$.

${ }^{2}$ Calculated values. 
analysis. Apparent digestibility of nutrients was measured using the indicator method according to the procedures of Sharifi et al. (2012).

On d 21 and 42, eight birds (one bird per cage) were randomly selected from each treatment, weighed and sacrificed by severing the jugular vein. Carcasses of the sacrificed birds were immediately opened and the entire intestine was removed aseptically. A 2-cm sample of the duodenum (at the midpoint region of duodenum), jejunum (midpoint between the bile duct entry and Meckel's diverticulum), and ileum (at the distal end of lower ileum) were collected. Each of these intestinal segments was flushed with physiological saline solution $(0.9 \% \mathrm{NaCl})$ to remove intestinal contents, fixed in $10 \%$ neutral buffered formalin, and kept at $4{ }^{\circ} \mathrm{C}$ prior to the microscopic assessment of intestinal morphology (Li et al., 2012). The cecum were isolated with nylon strings and removed. They were wrapped with new sterile gauze, immersed in liquid nitrogen and stored at $-80^{\circ} \mathrm{C}$ for subsequent enumeration of microbial populations.

\section{Chemical analysis}

Feed and dried excreta samples were ground to pass through a 40-mesh screen and mixed thoroughly. Samples were analyzed in duplicates for dry matter (DM) and crude protein $(\mathrm{CP})$ according to the standard methods of AOAC (1990). Gross energy (GE) content was measured using an automatic adiabatic oxygen bomb calorimeter (Parr 6300 Calorimeter; Moline, IL, USA). Chromium concentration in feed and excreta was analyzed using an atomic absorption spectrophotometer (Hitachi Z-2000 Automatic Absorption; Spectrophotometer, Tokyo, Japan) according to the method of Williams et al. (1962).

\section{Histological measurement}

Intestinal segments were cut into pieces not exceeding 2 $\mathrm{mm}$ in length and enclosed into a plastic tissue cassette. They were then dehydrated, cleared, and embedded in paraffin. For each intestinal segment, a 5- $\mu \mathrm{m}$ cross-section was obtained using a microtome and stained with hematoxylin and eosin. Villus height and crypt depth were measured at $40 \times$ magnification using a microscope (Olympus CK40; Olympus Optical Company, Shenzhen, China). Villus height was measured from the tip of the villus to the villus-crypt junction. Crypt depth was defined as the depth of the invagination between adjacent villi (Onderci et al., 2006). The villus height and crypt depth of 10 intact, well-oriented villi were measured per section.

\section{Microbial enumeration}

Frozen cecal digesta samples were thawed at room temperature. Approximately $1 \mathrm{~g}$ of cecal digesta was taken from each sample and serially diluted 10 -fold (from $10^{-1}$ to $\left.10^{-7}\right)$ with sterile physiological saline solution $(0.9 \% \mathrm{NaCl})$ and subsequently homogenized for 3 min using an ultraturrax. Dilutions were then plated onto selective agar medium for enumeration of target bacterial groups. Escherichia coli were grown on MacConkey agar (Beijing Aoboxing Bio-tech Co., Ltd., Beijing, China). Lactobacilli were cultivated using de Man, Rogosa, Sharpe agar (Oxoid Ltd., Hampshire, UK). Plates for Lactobacillus were incubated anaerobically, while plates for Escherichia coli were incubated aerobically. All plates were incubated at $37^{\circ} \mathrm{C}$ for $24 \mathrm{~h}$. Bacteria were enumerated by visual count of colonies, using the best replicate set from dilutions that resulted in 30 to 300 colonies per plate. The microbial enumerations of cecal digesta were expressed as base-10 logarithm colony-forming units per gram of cecal digesta.

\section{Statistical analysis}

All data were subjected to analysis of variance using the general linear model procedure of SAS (SAS Institute, 1999). Data on growth performance and apparent nutrient digestibility were analyzed using cage as the experimental unit, whereas intestinal morphology and cecal bacterial population data were analyzed using individual broiler as the experimental unit. Results were expressed as treatment means with their standard error of the means. Differences among treatments were separated by Duncan's multiple range tests, and identified by the least significant difference. Probability values less than 0.05 were considered significant.

\section{RESULTS}

\section{Growth performance}

Both the Bacillus amyloliquefaciens-based DFM and virginiamycin (AGP) treatments improved growth parameters over the whole experimental period (Table 2). From d 1 to 21, DFM 30, DFM 60, and AGP treatments showed better FCR $(\mathrm{p}<0.01)$ than the control diet. However, there were no significant differences in terms of BWG and FI. For the finisher phase and the overall period (d 1 to 42 ), chickens fed diets supplemented with Bacillus amyloliquefaciens-based DFM had higher BWG and better FCR than the control $(\mathrm{p}<0.05)$. The addition of virginiamycin significantly improved BWG, FI, and FCR during the finisher and overall period compared to the control group $(\mathrm{p}<0.05)$.

\section{Apparent total tract digestibility}

Supplementation of virginiamycin and Bacillus amyloliquefaciens-based DFM significantly increased $(\mathrm{p}<0.05)$ apparent total tract digestibility of $\mathrm{CP}, \mathrm{DM}$, and GE during the starter phase (Table 3). For the finisher phase, treatments AGP, DFM 30, and DFM 60 had significantly 
Table 2. Effect of Bacillus amyloliquefaciens-based direct-fed microbial (DFM) and virginiamycin (AGP) supplementation on the performance of broilers ${ }^{1}$

\begin{tabular}{|c|c|c|c|c|c|c|}
\hline \multirow{2}{*}{ Item } & \multicolumn{4}{|c|}{ Treatment $^{2}$} & \multirow{2}{*}{ SEM } & \multirow{2}{*}{ p-value } \\
\hline & Control & DFM 30 & DFM 60 & AGP & & \\
\hline \multicolumn{7}{|l|}{ Body weight gain (g/bird) } \\
\hline Starter phase (d 1 to 21$)$ & 637 & 664 & 649 & 669 & 8.81 & 0.07 \\
\hline Finisher phase (d 22 to 42 ) & $1,348^{\mathrm{c}}$ & $1,418^{\mathrm{b}}$ & $1,430^{\mathrm{b}}$ & $1,499^{\mathrm{a}}$ & 22.36 & $<0.01$ \\
\hline Overall experiment (d 1 to 42 ) & $1,985^{\mathrm{c}}$ & $2,082^{\mathrm{b}}$ & $2,079^{\mathrm{b}}$ & $2,168^{\mathrm{a}}$ & 23.40 & $<0.01$ \\
\hline \multicolumn{7}{|l|}{ Feed intake $(\mathrm{g} / \mathrm{bird})$} \\
\hline Starter phase (d 1 to 21$)$ & 991 & 1,004 & 985 & 1,006 & 12.93 & 0.62 \\
\hline Finisher phase ( $\mathrm{d} 22$ to 42 ) & $2,701^{\mathrm{b}}$ & $2,789^{\mathrm{ab}}$ & $2,786^{\mathrm{ab}}$ & $2,859^{\mathrm{a}}$ & 35.52 & $<0.05$ \\
\hline Overall experiment (d 1 to 42 ) & $3,692^{\mathrm{b}}$ & $3,793^{\mathrm{ab}}$ & $3,771^{\mathrm{ab}}$ & $3,865^{\mathrm{a}}$ & 37.58 & $<0.05$ \\
\hline \multicolumn{7}{|l|}{ Feed conversion ratio } \\
\hline Starter phase (d 1 to 21 ) & $1.56^{\mathrm{a}}$ & $1.51^{\mathrm{b}}$ & $1.52^{\mathrm{b}}$ & $1.50^{\mathrm{b}}$ & 0.01 & $<0.01$ \\
\hline Finisher phase (d 22 to 42 ) & $2.00^{\mathrm{a}}$ & $1.97^{\mathrm{ab}}$ & $1.95^{\mathrm{bc}}$ & $1.91^{\mathrm{c}}$ & 0.02 & $<0.05$ \\
\hline Overall experiment (d 1 to 42 ) & $1.86^{\mathrm{a}}$ & $1.82^{\mathrm{b}}$ & $1.81^{\mathrm{b}}$ & $1.78^{\mathrm{c}}$ & 0.01 & $<0.05$ \\
\hline
\end{tabular}

SEM, standard error of the mean.

${ }^{1}$ Data represent means from eight replicates per treatment.

${ }^{2}$ Control $=$ antibiotics-free basal diet; DFM $30=$ control supplemented with $30 \mathrm{mg} / \mathrm{kg}\left(7.5 \times 10^{7} \mathrm{cfu} / \mathrm{kg}\right)$ of DFM; DFM $60=$ control supplemented with 60 $\mathrm{mg} / \mathrm{kg}\left(1.5 \times 10^{8} \mathrm{cfu} / \mathrm{kg}\right)$ of DFM; AGP = control supplemented with $15 \mathrm{mg} / \mathrm{kg}$ of virginiamycin.

${ }^{a, b, c}$ Means in the same row with different superscripts are significantly different $(\mathrm{p}<0.05)$.

higher apparent total tract digestibility CP, DM, and GE compared with the control group $(\mathrm{p}<0.05)$. There were no statistical differences between the DFM 30, DFM 60, and AGP groups in the finisher phase.

\section{Intestinal morphology}

Results for broilers intestinal morphometric parameters are presented in Table 4, Figure 1 and 2. On d 21, villus height, crypt depth and villus height to crypt depth ratio of duodenum, jejunum, and ileum were significantly increased for birds fed with DFM (DFM 30 and DFM 60) compared to the control and virginiamycin groups $(\mathrm{p}<0.05)$. On $\mathrm{d} 42$, the addition of Bacillus amyloliquefaciens-based DFM significantly increased villus height (with the exception of DFM 30 in jejunum) and villus height to crypt depth ratio in all intestinal segments compared to both control and AGP treatments $(\mathrm{p}<0.05)$. It is interesting to note that the addition of virginiamycin resulted in similar or significantly lower $(p<0.05)$ villus height, crypt depth and villus height to crypt depth ratio compared to the control group.

\section{Microflora concentration}

Escherichia coli levels in the cecum were significantly reduced by dietary supplementation of Bacillus amyloliquefaciens-based DFM and virginiamycin on d 21 and 42 ( $\mathrm{p}<0.01$; Table 5). Birds from the DFM 30 and DFM 60 groups had significantly higher viable counts of Lactobacillus than control group $(\mathrm{p}<0.01)$, whereas birds fed diets supplemented with virginiamycin had lower concentration of Lactobacillus in the cecum compared to

Table 3. Effect of Bacillus amyloliquefaciens-based direct-fed microbial (DFM) and virginiamycin (AGP) supplementation on the apparent total tract nutrients digestibility $(\%)$ in broilers ${ }^{1}$

\begin{tabular}{|c|c|c|c|c|c|c|}
\hline \multirow{2}{*}{ Item } & \multicolumn{4}{|c|}{ Treatment $^{2}$} & \multirow{2}{*}{ SEM } & \multirow{2}{*}{ p-value } \\
\hline & Control & DFM 30 & DFM 60 & AGP & & \\
\hline \multicolumn{7}{|l|}{ d 21} \\
\hline Crude protein & $58.86^{\mathrm{b}}$ & $64.69^{a}$ & $64.06^{\mathrm{a}}$ & $65.47^{\mathrm{a}}$ & 0.77 & $<0.01$ \\
\hline Dry matter & $68.22^{c}$ & $72.45^{\mathrm{a}}$ & $70.30^{b}$ & $72.71^{\mathrm{a}}$ & 0.58 & $<0.01$ \\
\hline Gross energy & $72.22^{c}$ & $75.34^{\mathrm{ab}}$ & $74.07^{\mathrm{b}}$ & $75.98^{\mathrm{a}}$ & 0.47 & $<0.01$ \\
\hline \multicolumn{7}{|l|}{$\mathrm{d} 42$} \\
\hline Crude protein & $52.46^{\mathrm{b}}$ & $58.48^{\mathrm{a}}$ & $59.11^{\mathrm{a}}$ & $60.69^{\mathrm{a}}$ & 1.07 & $<0.01$ \\
\hline Dry matter & $68.43^{b}$ & $71.18^{\mathrm{a}}$ & $72.19^{\mathrm{a}}$ & $72.59^{\mathrm{a}}$ & 0.61 & $<0.01$ \\
\hline Gross energy & $72.85^{b}$ & $75.19^{a}$ & $76.18^{\mathrm{a}}$ & $76.27^{\mathrm{a}}$ & 0.56 & $<0.01$ \\
\hline
\end{tabular}

SEM, standard error of the mean.

${ }^{1}$ Data represent means from eight replicates per treatment.

${ }^{2}$ Control = antibiotics-free basal diet; DFM $30=$ control supplemented with $30 \mathrm{mg} / \mathrm{kg}\left(7.5 \times 10^{7} \mathrm{cfu} / \mathrm{kg}\right)$ of DFM; DFM $60=$ control supplemented with 60 $\mathrm{mg} / \mathrm{kg}\left(1.5 \times 10^{8} \mathrm{cfu} / \mathrm{kg}\right)$ of DFM; AGP = control supplemented with $15 \mathrm{mg} / \mathrm{kg}$ of virginiamycin.

${ }^{\mathrm{a}, \mathrm{b}, \mathrm{c}}$ Means in the same row with different superscripts are significantly different $(\mathrm{p}<0.05)$. 
Table 4. Effect of Bacillus amyloliquefaciens-based direct-fed microbial (DFM) and virginiamycin (AGP) supplementation on intestinal morphometric parameters in broilers 1

\begin{tabular}{|c|c|c|c|c|c|c|c|}
\hline \multirow{2}{*}{ Item } & & \multicolumn{4}{|c|}{ Treatment $^{2}$} & \multirow{2}{*}{ SEM } & \multirow{2}{*}{ p-value } \\
\hline & & Control & DFM 30 & DFM 60 & AGP & & \\
\hline \multicolumn{8}{|l|}{$\mathrm{d} 21$} \\
\hline \multirow[t]{3}{*}{ Duodenum } & Villus height $(\mu \mathrm{m})$ & $1,133^{\mathrm{c}}$ & $1,439^{\mathrm{b}}$ & $1,529^{\mathrm{a}}$ & $1,009^{\mathrm{d}}$ & 18.61 & $<0.01$ \\
\hline & Crypt depth $(\mu \mathrm{m})$ & $129^{\mathrm{b}}$ & $148^{\mathrm{a}}$ & $152^{\mathrm{a}}$ & $121^{\mathrm{c}}$ & 2.66 & $<0.01$ \\
\hline & Villus height to crypt depth ratio & $8.83^{\mathrm{b}}$ & $9.71^{\mathrm{a}}$ & $10.04^{\mathrm{a}}$ & $8.37^{\mathrm{c}}$ & 0.15 & $<0.01$ \\
\hline \multirow[t]{3}{*}{ Jejunum } & Villus height $(\mu \mathrm{m})$ & $686^{\mathrm{c}}$ & $824^{\mathrm{b}}$ & $922^{\mathrm{a}}$ & $601^{\mathrm{d}}$ & 15.15 & $<0.01$ \\
\hline & Crypt depth $(\mu \mathrm{m})$ & $105^{\mathrm{b}}$ & $113^{\mathrm{a}}$ & $118^{\mathrm{a}}$ & $102^{\mathrm{b}}$ & 2.10 & $<0.01$ \\
\hline & Villus height to crypt depth ratio & $6.51^{\mathrm{c}}$ & $7.33^{\mathrm{b}}$ & $7.83^{\mathrm{a}}$ & $5.92^{\mathrm{d}}$ & 0.14 & $<0.01$ \\
\hline \multirow[t]{3}{*}{ Ileum } & Villus height $(\mu \mathrm{m})$ & $363^{\mathrm{c}}$ & $457^{\mathrm{a}}$ & $488^{\mathrm{a}}$ & $315^{\mathrm{d}}$ & 6.45 & $<0.01$ \\
\hline & Crypt depth $(\mu \mathrm{m})$ & $109^{\mathrm{b}}$ & $122^{\mathrm{a}}$ & $128^{\mathrm{a}}$ & $104^{\mathrm{b}}$ & 3.74 & $<0.01$ \\
\hline & Villus height to crypt depth ratio & $3.34^{\mathrm{b}}$ & $3.74^{\mathrm{a}}$ & $3.81^{\mathrm{a}}$ & $3.08^{\mathrm{b}}$ & 0.10 & $<0.01$ \\
\hline \multicolumn{8}{|l|}{ d 42} \\
\hline \multirow[t]{3}{*}{ Duodenum } & Villus height $(\mu \mathrm{m})$ & $1,179^{\mathrm{c}}$ & $1,259^{\mathrm{b}}$ & $1,379^{\mathrm{a}}$ & $1,035^{\mathrm{d}}$ & 19.93 & $<0.01$ \\
\hline & Crypt depth $(\mu \mathrm{m})$ & $138^{\mathrm{ab}}$ & $132^{\mathrm{b}}$ & $142^{\mathrm{a}}$ & $124^{\mathrm{c}}$ & 2.31 & $<0.01$ \\
\hline & Villus height to crypt depth ratio & $8.56^{\mathrm{b}}$ & $9.53^{\mathrm{a}}$ & $9.71^{\mathrm{a}}$ & $8.38^{\mathrm{b}}$ & 0.12 & $<0.01$ \\
\hline \multirow[t]{3}{*}{ Jejunum } & Villus height $(\mu \mathrm{m})$ & $699^{\mathrm{b}}$ & $737^{\mathrm{ab}}$ & $759^{\mathrm{a}}$ & $655^{\mathrm{c}}$ & 14.07 & $<0.01$ \\
\hline & Crypt depth $(\mu \mathrm{m})$ & 124 & 124 & 122 & 121 & 2.07 & 0.72 \\
\hline & Villus height to crypt depth ratio & $5.64^{\mathrm{b}}$ & $5.97^{\mathrm{a}}$ & $6.23^{\mathrm{a}}$ & $5.40^{\mathrm{b}}$ & 0.11 & $<0.01$ \\
\hline \multirow[t]{3}{*}{ Ileum } & Villus height $(\mu \mathrm{m})$ & $467^{\mathrm{b}}$ & $527^{\mathrm{a}}$ & $535^{\mathrm{a}}$ & $446^{\mathrm{b}}$ & 10.14 & $<0.01$ \\
\hline & Crypt depth $(\mu \mathrm{m})$ & 104 & 102 & 102 & 105 & 1.66 & 0.70 \\
\hline & Villus height to crypt depth ratio & $4.48^{\mathrm{b}}$ & $5.16^{\mathrm{a}}$ & $5.22^{\mathrm{a}}$ & $4.26^{\mathrm{b}}$ & 0.08 & $<0.01$ \\
\hline
\end{tabular}

SEM, standard error of the mean.

${ }^{1}$ Data represent means from six replicates per treatment.

${ }^{2}$ Control = antibiotics-free basal diet; DFM $30=$ control supplemented with $30 \mathrm{mg} / \mathrm{kg}\left(7.5 \times 10^{7} \mathrm{cfu} / \mathrm{kg}\right)$ of DFM; DFM $60=$ control supplemented with 60 $\mathrm{mg} / \mathrm{kg}\left(1.5 \times 10^{8} \mathrm{cfu} / \mathrm{kg}\right)$ of DFM; AGP = control supplemented with $15 \mathrm{mg} / \mathrm{kg}$ of virginiamycin.

a,b,c,d Means in the same row with different superscripts are significantly different $(\mathrm{p}<0.05)$.

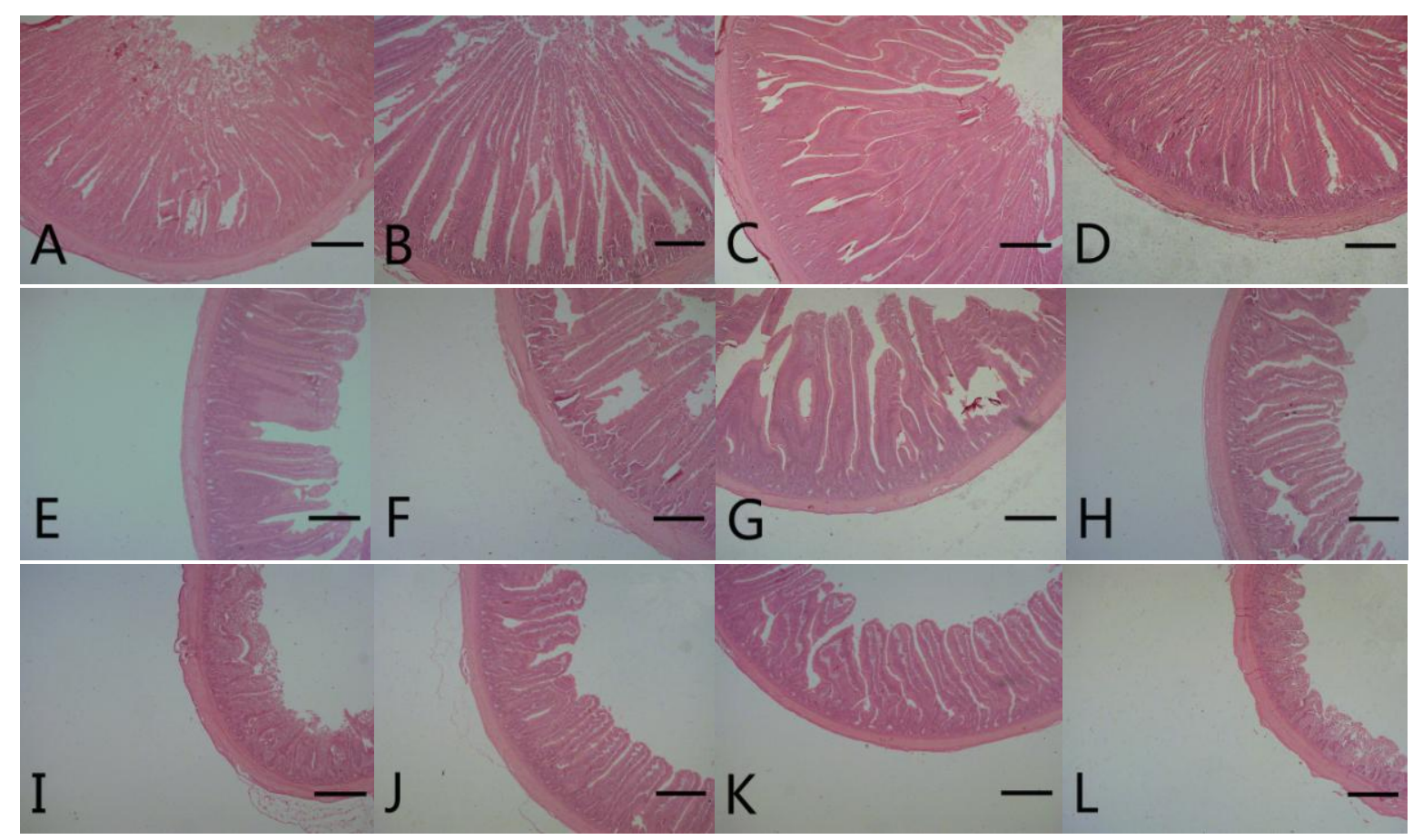

Figure 1. Photomicrograph of intestinal segments from broiler chickens at $21 \mathrm{~d}$ of age. A, B, C, and D represent the duodenum from control (antibiotics-free basal diet), DFM 30 (control supplemented with $30 \mathrm{mg} / \mathrm{kg}$ of Bacillus amyloliquefaciens-based direct-fed microbial), DFM 60 (control supplemented with $30 \mathrm{mg} / \mathrm{kg}$ of Bacillus amyloliquefaciens-based direct-fed microbial, AGP (control supplemented with $15 \mathrm{mg} / \mathrm{kg}$ of virginiamycin), respectively. E, F, G, and $\mathrm{H}$ represent the jejunum from control, FDM 30, FDM 60, and AGP, respectively. I, J, K, and L represent the jejunum from control, FDM 30, FDM 60, and AGP, respectively. Stained with hematoxylin and eosin; Bar $=300 \mu \mathrm{m}$. DFM, direct-fed microbial; AGP, antibiotic growth promoter. 


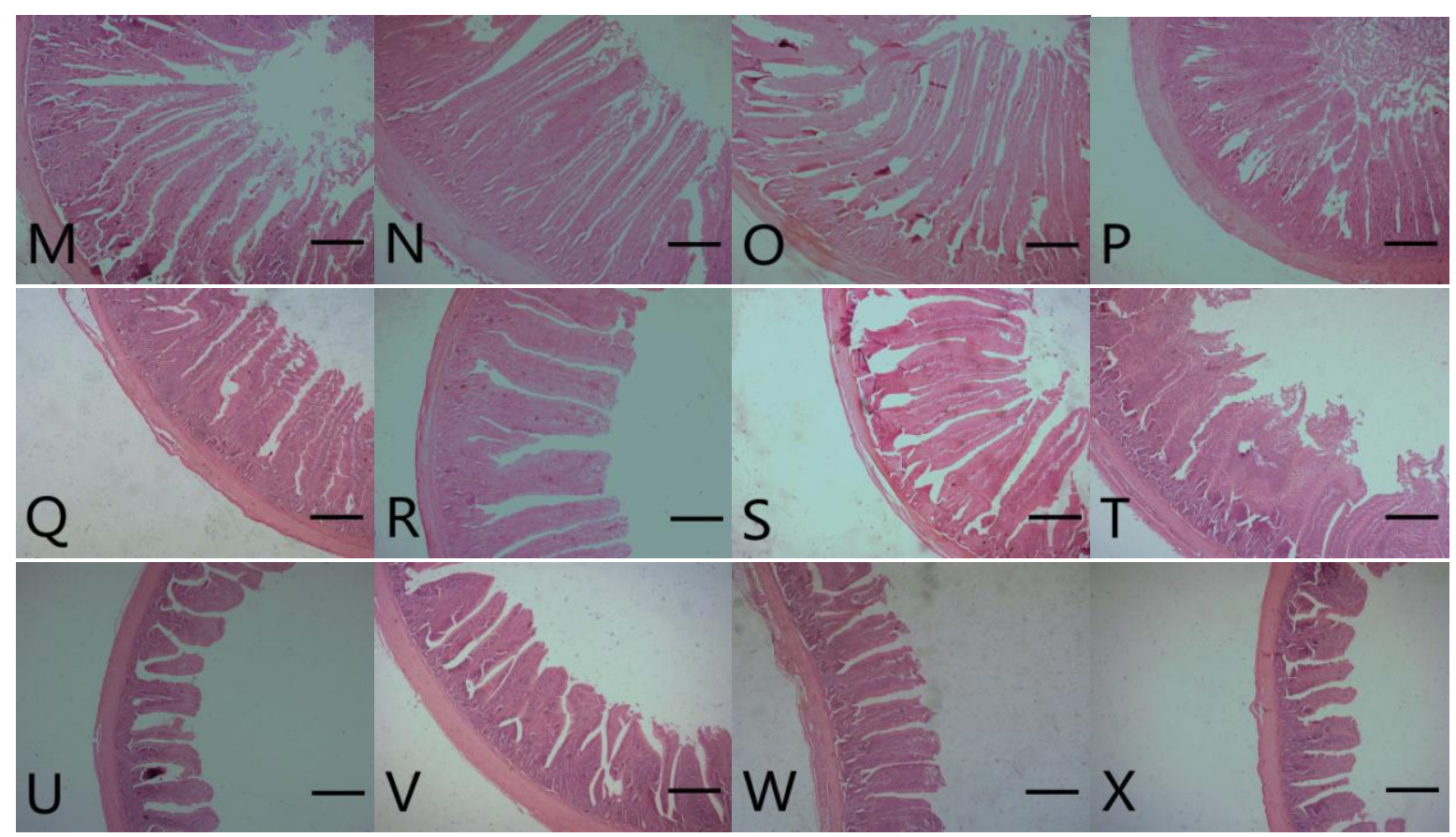

Figure 2. Photomicrograph of intestinal segments from broiler chickens at $42 \mathrm{~d}$ of age. $\mathrm{M}, \mathrm{N}, \mathrm{O}$ and $\mathrm{P}$ represent the duodenum from control (antibiotics-free basal diet), DFM 30 (control supplemented with $30 \mathrm{mg} / \mathrm{kg}$ of Bacillus amyloliquefaciens-based direct-fed microbial), DFM 60 (control supplemented with $30 \mathrm{mg} / \mathrm{kg}$ of Bacillus amyloliquefaciens-based direct-fed microbial, AGP (control supplemented with $15 \mathrm{mg} / \mathrm{kg}$ of virginiamycin), respectively. Q, R, S and T represent the jejunum from control, FDM 30, FDM 60, and AGP, respectively. U, V, W and X represent the jejunum from control, FDM 30, FDM 60, and AGP, respectively. Stained with hematoxylin and eosin; Bar $=300 \mu \mathrm{m}$. DFM, direct-fed microbial; AGP, antibiotic growth promoter.

both control and Bacillus amyloliquefaciens-based DFM groups.

\section{DISCUSSION}

Results from the present trial support the hypothesis that feeding DFMs can improve the performance of broilers fed antibiotic-free diets, as evidenced by the better BWG and FCR values. However, there is still a lot of debate in scientific literature regarding the ability of DFMs to replace AGPs. For instance, unlike the present study, Jerzsele et al.
(2012) reported no effect of DFMs on the performance of broilers. The improvement in broiler growth is probably the consequence of increased nutrient digestibility, improved intestinal morphology and balanced microbial flora (Isolauri et al., 2001).

Indeed, this study showed that the apparent digestibility of DM, CP, and GE in treatments DFM 30 and DFM 60 broiler were increased compared with those in the control group. While the main functions of the gut are to digest feed and absorb nutrients, water and electrolytes (Fioramonti et al., 2003), it is also known to be the largest immune organ

Table 5. Effect of Bacillus amyloliquefaciens-based direct-fed microbial (DFM) and virginiamycin (AGP) supplementation on cecal microflora composition of broilers (log cfu/g of wet digesta) ${ }^{1}$

\begin{tabular}{|c|c|c|c|c|c|c|}
\hline \multirow{2}{*}{ Item } & \multicolumn{4}{|c|}{ Treatment $^{2}$} & \multirow{2}{*}{ SEM } & \multirow{2}{*}{$\mathrm{p}$-value } \\
\hline & Control & DFM 30 & DFM 60 & AGP & & \\
\hline \multicolumn{7}{|l|}{ d 21} \\
\hline Escherichia coli & $6.83^{\mathrm{a}}$ & $5.72^{b}$ & $5.68^{b}$ & $5.54^{\mathrm{c}}$ & 0.05 & $<0.01$ \\
\hline Lactobacillus & $7.61^{b}$ & $8.33^{\mathrm{a}}$ & $8.41^{\mathrm{a}}$ & $6.87^{\mathrm{c}}$ & 0.10 & $<0.01$ \\
\hline \multicolumn{7}{|l|}{$\mathrm{d} 42$} \\
\hline Escherichia coli & $6.99^{\mathrm{a}}$ & $6.14^{b}$ & $6.11^{b}$ & $5.91^{\mathrm{c}}$ & 0.06 & $<0.01$ \\
\hline Lactobacillus & $7.88^{\mathrm{b}}$ & $8.31^{\mathrm{a}}$ & $8.47^{\mathrm{a}}$ & $7.12^{c}$ & 0.09 & $<0.01$ \\
\hline
\end{tabular}

SEM, standard error of the mean.

${ }^{1}$ Data represent means from six replicates per treatment.

${ }^{2}$ Control = antibiotics-free basal diet; DFM 30 = control supplemented with $30 \mathrm{mg} / \mathrm{kg}\left(7.5 \times 10^{7} \mathrm{cfu} / \mathrm{kg}\right)$ of DFM; DFM $60=$ control supplemented with 60 $\mathrm{mg} / \mathrm{kg}\left(1.5 \times 10^{8} \mathrm{cfu} / \mathrm{kg}\right)$ of DFM; AGP = control supplemented with $15 \mathrm{mg} / \mathrm{kg}$ of virginiamycin.

${ }^{a, b, c}$ Means in the same row with different superscripts are significantly different $(\mathrm{p}<0.05)$. 
in the body (Chichlowski et al., 2007). The structure and integrity of the intestinal epithelium are important factors contributing to gut health and subsequent digestive capacity. It is generally recognized that villus height is a good indicator of the function and activation of intestinal villus (Shamoto and Yamauchi, 2000). Better villus height and villus height to crypt depth ratio suggest an improvement in the nutrient digestibility and absorption capacity of the small intestine (Montagne et al., 2003). The present study showed that Bacillus amyloliquefaciens-based DFM improved gut structure and resulted in a greater absorption surface, as indicated by improved villus height and villus height to crypt depth ratio in the different small intestinal segments compared to the AGP-free control diet. Other evidences supporting the effect of DFMs on gut structure and integrity can be found in the scientific literature. Jayaraman et al. (2013) reported that the inclusion of Bacillus subtilis in broiler diets led to better villus height and villus height to crypt depth ratio. It was suggested the height of villus and the ratio of villus height to crypt depth are related to the epithelial cell turnover (Fan et al., 1997). The presence of inflammation from pathogens or their toxins will cause the rapid epithelial cell turnover (Deng et al., 2012). The suppression of pathogenic bacteria by Bacillus amyloliquefaciens-based DFM may result in the better villus height and villus height to crypt depth ratio.

The better performance of broilers fed with DFMs can also be the result of a positive modulation of the gut microbiota (Keeney and Finlay, 2011). In the gastrointestinal tract, numerous microorganisms co-exist and constitute a symbiotic ecosystem in equilibrium (Choct, 2009). Various trials have demonstrated that DFMs can positively modulate the composition of the intestinal microflora of chickens via the stimulation of potentially beneficial populations and/or the reduction of potentially pathogenic bacteria (Maruta et al., 1996). In the present study, caecal digesta samples of birds fed a diet with Bacillus amyloliquefaciens-based DFM had higher Lactobacillus concentration as well as a reduction of Escherichia coli counts. Bacillus species grows only under aerobic conditions and consumes oxygen rapidly (Baruzzi et al., 2011; Geng et al., 2011). The consumption of oxygen will create a more favorable environment for beneficial anaerobic species (Song et al., 2014). In addition, Bacillus amyloliquefaciens-based DFM may reduce the $\mathrm{pH}$ value inside the intestine, which is favorable to the colonization Lactobacilli and the suppression of Escherichia coli (Wu et al., 2011).

The need to reduce the use of AGPs has driven our industry to look for alternatives in order to maintain animal health and performance. The DFMs-based solutions have emerged as a promising candidate. However, there is still some controversy about the possibility to fully replace
AGPs without depressing bird performance. Nonetheless, the ban of AGPs is already a reality in different parts of the world. In such a situation, the present work showed that the addition of Bacillus amyloliquefaciens-based DFM can help producers to improve gut health and subsequent bird performance. It is interesting to note that, in this study, virginiamycin decreased both the concentrations of cecal Lactobacillus and Escherichia coli. While AGPs are known to modify intestinal microbiota and eliminate or reduce the populations of pathogens and bacteria that compete with the host for nutrients, consequently enhancing growth, they can also reduce the levels of beneficial bacteria such as Lactobacillus. This may interfere with the ecological balance of the normal intestinal microflora and create opportunities for pathogens to infect the host and lead to serious disease (Gaskins et al., 2002).

In conclusion, results from the present study indicate that supplementation with $30 \mathrm{mg} / \mathrm{kg}$ and $60 \mathrm{mg} / \mathrm{kg}$ of Bacillus amyloliquefaciens-based DFM improved growth performance of broilers fed plant protein-based diets. This improvement was associated with the positive effect of nutrient utilization, intestinal morphology and cecal microflora. Therefore, under the condition of the present research, Bacillus amyloliquefaciens-based DFM appears to be promising alternative to the use of AGPs in broiler diets.

\section{REFERENCES}

Aliakbarpour, H. R., M. Chamani, G. Rahimi, A. A. Sadeghi, and D. Qujieq. 2012. The Bacillus subtilis and lactic acid bacteria probiotics influences intestinal mucin gene expression, histomorphology and growth performance in broilers. Asian Australas. J. Anim. Sci. 25:1285-1293.

Alloui, M. N., W. Szczurek, and S. Świątkiewicz. 2013. The usefulness of prebiotics and probiotics in modern poultry nutrition: A review. Ann. Anim. Sci. 13:17-32.

An, B. K., B. L. Cho, S. J. You, H. D. Paik, H. I. Chang, S. W. Kim, C. W. Yun, and C. W. Kang. 2008. Growth performance and antibody response of broiler chicks fed yeast derived $\beta$ glucan and single-strain probiotics. Asian Australas. J. Anim. Sci. 21:1027-1032.

AOAC. 1990. Official Methods of Analysis. 16th ed. Association of Official Analytical Chemists, Washington, DC, USA.

Baruzzi, F., L. Quintieri, M. Morea, and L. Caputo. 2011. Antimicrobial compounds produced by Bacillus spp. and applications in food. Science against microbial pathogens: Communicating Current research and technological advances (Ed. A. M. Vilas). City, Spain. 1102-1111.

Castanon, J. I. R. 2007. History of the use of antibiotic as growth promoters in European poultry feeds. Poult. Sci. 86:2466-2471.

Chichlowski, M., J. Croom, B. W. McBride, G. B. Havenstein, and M. D. Koci. 2007. Mebabolic and physiological impact of probiotics or direct-fed-microbials on poultry: a brief review of current knowledge. Int. J. Poult. Sci. 6:694-704.

Choct, M. 2009. Managing gut health through nutrition. Br. Poult. Sci. 50:9-15. 
Deng, W., X. F. Dong, J. M. Tong, and Q. Zhang. 2012. The probiotic Bacillus licheniformis ameliorates heat stressinduced impairment of egg production, gut morphology, and intestinal mucosal immunity in laying hens. Poult. Sci. 91:575582.

Fan, Y., J. Croom, V. L. Christensen, B. L. Black, A. R. Bird, L. R. Daniel, B. W. McBride, and E. J. Eisen. 1997. Jejunal glucose uptake and oxygen consumption in turkey poults selected for rapid growth. Poult. Sci. 76:1738-1745.

Ferreira, C. L., S. salminen, L. Grzeskowiak, M. A. Brizuela, L. Sanchez, H. Carneiro, and M. Bonnet. 2011. Terminology concepts of probiotic and prebiotic and their role in human and animal health. Rev. Salud Anim. 33:137-146.

Fioramonti, J., V. Theodorou, and L. Bueno. 2003. Probiotics: what are they? What are their effects on gut physiology? Best Pract. Res Cl. Gastroenterol. 17:711-724.

Fuller, R. F. 1989. Probiotic in man and animals. J. Appl. Bacteriol. 66:365-378.

Gaskins, H. R., C. T. Collier, and D. B. Anderson. 2002. Antibiotics as growth promotants: Mode of action. Anim. Biotechnol. 13:29-42.

Geng, W., M. Cao, C Song, H. Xie, L. Liu, C. Yang, J. Feng, W. Zhang, Y. Jin, Y. Du, and S. Wang. 2011. Complete genome sequence of Bacillus amyloliquefaciens LL3, which exhibits glutamic acid-independent production of poly- $\gamma$-glutamic acid. J. Bacteriol. 193:3393-3394.

Hong, H. A., L. H. Duc, and S. M. Cutting. 2005. The use of bacterial spore formers as probiotics. FEMS Microbiol. Rev. 29:813-835.

Huyghebaert, G., R. Ducatelle, and F. V. Immerseel. 2011. An update alternatives to antimicrobial growth promoters for broilers. Vet. J. 187:182-188.

Isolauri, E., Y. Sütas, P. Kankaanpää, H. Arvilommi, and S. Salminen. 2001. Probiotics: effects on immunity. Am. J. Clin. Nutr. 73:444S-450S.

Jayaraman, S., G. Thangavel, H. Kurian, R. Mani, R. Mukkalil, and H. Chirakkal. 2013. Bacillus subtilis PB6 improves intestinal health of broiler chickens challenged with Clostridium perfringens-induced necrotic enteritis. Poult. Sci. 92:370-374.

Jerzsele, A., K. Szeker, R. Csizinszky, E. Gere, C. Jakab, J. J. Mallo, and P. Galfi. 2012. Efficacy of protected sodium butyrate, a protected blend of essential oils, their combination, and Bacillus amyloliquefaciens spore suspension against artificially induced necrotic enteritis in broilers. Poult. Sci. 91:837-843.
Keeney, K. M. and B. B. Finlay. 2011. Enteric pathogen exploitation of the microbiota-generated nutrient environment of the gut. Curr. Opin. Microbiol. 14:92-98.

Li, P. F., X. S. Piao, Y. J. Ru, X. Han, L. F. Xue, and H. Y. Zhang. 2012. Effects of adding essential oil to the diet of weaned pigs on performance, nutrient utilization, immune response and intestinal health. Asian Australas. J. Anim. Sci. 25:1617-1626.

Maruta, K., H. Miyazaki, Y. Tadano, S. Masuda, A. Suzuki, H. Takahashi, and M. Takahashi. 1996. Effects of Bacillus subtilis C-3102 intake on fecal flora of sows and on diarrhea and mortality rate of their piglets. Anim. Sci. Technol. 67:403-409.

Montagne, L., J. R. Pluske, and D. J. Hampson. 2003. A review of interactions between dietary fibre and the intestinal mucosa, and their consequences on digestive health in young nonruminant animals. Anim. Feed Sci. Technol. 108:95-117.

NRC. 1994. Nutrient Requirements of Poultry. 9th rev. ed. National Academy Press, Washington, DC, USA.

Onderci, M., N. Sahin, K. Sahin, G. Cikim, A. Aydin, I. Ozercanand, and S. Aydin. 2006. Efficacy of supplementation of $\alpha$-amylase-producing bacterial culture on the performance, nutrient use, and gut morphology of broiler chickens fed a corn-based diet. Poult. Sci. 85:505-510.

SAS. Institute. 1999. SAS User's Guide: Statistics (Version 8.01). SAS Inst. Inc., Cary, NC, USA.

Shamoto, K. and K. Yamauchi. 2000. Recovery responses of chick intestinal villus morphology to different refeeding procedures. Poult. Sci. 79:718-723.

Sharifi, S. D., A. Dibamehr, H. Lotfollahian, and B. Baurhoo. 2012. Effects of flavomycin and probiotic supplementation to diets containing different sources of fat on growth performance, intestinal morphology, apparent metabolizable energy, and fat digestibility in broiler chickens. Poult. Sci. 91:918-927.

Song, J., K. Xiao, Y. L. Ke, L. F. Jiao, C. H. Hu, Q. Y. Diao, B. Shi, and X. T. Zhou. 2014. Effect of a probiotic mixture on intestinal microflora, morphology, and barrier interity of broilers subjected to heat stress. Poult. Sci. 93:581-588.

Williams, C. H., D. J. David, and O. Lismaa. 1962. The determination of chromic oxide in faeces sample by atomic absorption spectrophotometry. J. Agric. Sci. 59:381-385.

Wu, B. Q., T. Zhang, L. Q. Guo, and J. F. Lin. 2011. Effect of Bacillus subtilis $\mathrm{KD}_{1}$ on broiler intestinal flora. Poult. Sci. 90:2493-2499. 